\title{
Fatores ambientais que afetam a produção e a composição do leite em rebanhos assistidos por cooperativas no Rio Grande do Sul
}

\author{
Giovani Noroํㅜ, Félix Hilario Diaz González², Rómulo Campos ${ }^{3}$, João Walter Dürr ${ }^{4}$ \\ ${ }^{1}$ Cooperativa Cotribá, Ibirubá (RS). \\ ${ }^{2}$ Laboratório de Análises Clínicas Veterinárias - Universidade Federal do Rio Grande do Sul, Porto Alegre (RS) \\ 3 Universidade Nacional da Colômbia, Palmira (Colômbia). \\ ${ }^{4}$ Serviço de Análises de Rebanhos Leiteiros - Universidade de Passo Fundo, Passo Fundo (RS).
}

\begin{abstract}
RESUMO - Neste estudo, avaliaram-se os efeitos de alguns fatores ambientais sobre a produção, a composição química e a contagem de células somáticas do leite em rebanhos vinculados às cooperativas no Rio Grande do Sul. Foram utilizados dados de um programa de controle leiteiro durante cinco anos, totalizando 165.311 observações, para analisar os seguintes efeitos ambientais: ano e mês do controle leiteiro, idade ao parto, tempo em controle leiteiro e estádio da lactação. A produção média de leite foi de 19,36 L/vaca/dia. Foi encontrada maior produção de leite em vacas de 5 a 6 anos de idade ao parto, nos primeiros 60 dias de lactação, nos meses de inverno e em rebanhos com mais tempo em controle leiteiro. Maior número de células somáticas foi relacionado à redução na produção de leite. Houve menor teor de gordura e de proteína no leite nos primeiros 60 dias de lactação e aumento desses componentes com o aumento no número de células somáticas. A concentração de lactose no leite diminuiu significativamente à medida que aumentaram as células somáticas e a idade ao parto. A contagem de células somáticas aumentou com a idade da vaca e à medida que avançou a lactação. Nos meses de inverno, verificaram-se valores mais elevados de proteína, gordura e lactose, possivelmente como conseqüência da alimentação com gramíneas temperadas Os resultados revelam a importância das variações ambientais no estudo da composição do leite.
\end{abstract}

Palavras-chave: células somáticas, composição do leite, fatores ambientais, Sul do Brasil

\section{Effects of environmental factors on milk yield and composition of dairy herds assisted by cooperatives in Rio Grande do Sul, Brazil}

\begin{abstract}
The effects of some environmental factors on milk yield and milk chemical composition and also on somatic cells count in dairy herds assisted by cooperatives (DHI) in Rio Grande do Sul, Brazil were investigated in this trial. Data were obtained from a 5-year period of dairy control program totalizing 165,311 observations and were used to investigate the effects of year and month of dairy control, age at calving, time of farm on dairy control and stage of lactation on milk yield and composition. Milk yield including all observations averaged $19.36 \mathrm{~L} / \mathrm{cow} /$ day. Greater milk yield was observed in cows varying from 5 to 6 years of age at calving, at the first 60 days of lactation, in the winter months and in herds with longer time in dairy control. Increased somatic cells count was associated to reduction in milk yield. Lower contents of milk fat and milk protein and greater somatic cells number were observed at the first 60 days of lactation. Concentration of milk lactose decreased with both the increment in somatic cells count and age at calving. Somatic cells count increased as the age of cows advanced and as lactation progressed. Milk contents of protein, fat and lactose all increased during the winter months possibly because of feeding temperate grasses. Results from this study showed that is important taking into account the effects of environmental factors on milk composition.
\end{abstract}

Key Words: environment, milk composition, somatic cells, southern Brazil

\section{Introdução}

O estado do Rio Grande do Sul (RS) é atualmente o terceiro maior produtor de leite no Brasil, com produção anual superior a 2,3 bilhões de litros (IBGE, 2004). A produção de leite neste estado vem crescendo em escala e produtividade nos últimos anos, principalmente nas bacias leiteiras ligadas às cooperativas, responsáveis pela maioria da captação. A região noroeste do RS é responsável por aproximadamente $65 \%$ da produção deste estado (Bittencourt et al., 2000).

O conhecimento da composição do leite é essencial para a determinação de sua qualidade, pois define diversas propriedades organolépticas e industriais. Os parâmetros de qualidade são cada vez mais utilizados para detecção de falhas nas práticas de manejo, servindo como referência na 
valorização da matéria-prima (Dürr, 2004). Os principais parâmetros utilizados pela maioria dos programas de qualidade industrial do leite são os conteúdos de gordura, proteína, sólidos totais e a contagem de células somáticas (Monardes, 1998).

As produções de leite e gordura do leite em vacas da raça Holandesa apresenta variabilidade nos trabalhos encontrados na literatura. Alguns estudos realizados no Brasil descrevem a variabilidade no conteúdo de gordura do leite de vacas (González \& Campos, 2003). No Brasil, a produção total de leite e o teor de gordura são as características mais enfatizadas pelos serviços de controle leiteiro (Santos \& Fonseca. 2002), enquanto diversos países, nos últimos anos, têm valorizado o teor de proteína utilizando este critério nos sistemas de pagamento por qualidade. Esta tendência se explica porque, enquanto a gordura teve sua preferência reduzida pelos hábitos de consumo da população, a proteína tem sido valorizada por ser determinante do rendimento industrial de derivados lácteos (Monardes, 1998).

Os fatores ambientais que afetam o teor de lactose no leite têm sido pouco estudados, talvez por sua menor importância na produção de queijos e outros derivados lácteos ou por sua menor variação de acordo com os fatores nutricionais e ambientais (Sutton, 1989). A contagem de células somáticas no leite é um indicador da incidência de mastite subclínica aceito internacionalmente como medida para determinar a qualidade microbiológica do leite (Ostrensky et al., 2000).

Neste estudo, avaliaram-se os efeitos de fatores ambientais sobre a produção de leite, a concentração de proteína, gordura e lactose e a contagem de células somáticas em amostras de leite provenientes de rebanhos vinculados às cooperativas da região noroeste do Rio Grande do Sul.

\section{Material e Métodos}

Este trabalho foi desenvolvido a partir de dados de um Programa de Gerenciamento de Rebanhos Leiteiros no Sul do Brasil. Foram utilizados dados de produção pertencentes a 259 rebanhos leiteiros selecionados, ligados a quatro cooperativas da região noroeste do estado. No total, foram utilizadas 165.311 observações, coletadas entre janeiro/1998 e julho/2003. Estas cooperativas se caracterizam pela produção de grãos (soja e milho no verão; trigo, cevada e aveia no inverno), principal atividade econômica da região. A atividade leiteira é expressiva, sendo desenvolvida no sistema de integração lavoura e pecuária. Os rebanhos avaliados neste estudo podem ser definidos dentro do sistema pastoril, com suplementação de silagens e concentrados.
As análises da composição química do leite incluíram lactose, gordura e proteína, mediante técnica do infravermelho próximo (NIRS, Bentley 2000, Bentley Instruments, EUA) e a contagem de células somáticas (CCS), mediante citometria de fluxo (Somacount 300, Bentley Instruments, EUA). Os dados de produção de leite foram obtidos a partir dos relatórios do Programa Leiteiro nos rebanhos selecionados.

No modelo estatístico, foram utilizados os seguintes efeitos ambientais: ano de controle leiteiro (1998 a 2003), mês do controle leiteiro (janeiro a dezembro), idade ao parto (seis categorias), tempo em controle leiteiro do rebanho ( 1 a 5 ou mais anos) e estádio da lactação ( $<60$ dias, 61-120 dias, 121-220 dias e >221 dias). Foi observado o efeito da contagem de células somáticas sobre a produção e a composição do leite, sendo realizada transformação de CCS em escore de células somáticas (ECS), com base na amplitude de variação da CCS, conforme Shook (1982), que estabelece escores entre 0 e 9 . Para cada efeito ambiental, foi realizada análise de variância utilizando-se o procedimento General Linear Model do programa estatístico SAS (2001).

\section{Resultados e Discussão}

Na Tabela 1 são apresentados os valores totais (média, desvio-padrão e coeficiente de variação) da produção e composição do leite e do escore de células somáticas nos 259 rebanhos. A produção média de leite foi de 19,36 L/vaca/ dia. Nas diferentes cooperativas, a produção variou de 18,4 a $25 \mathrm{~L} / \mathrm{vaca} / \mathrm{dia}$. O escore de células somáticas (ECS) mostrou efeito significativo sobre a produção de leite, sendo que, entre os escores 0 a 6 , ocorreu decréscimo na produção à medida que o escore aumentou. Foi observado aumento significativo na produção de leite entre os anos de controle leiteiro de 1998 a 2000. A produção de leite diminuiu à medida que avançou o estádio de lactação. A idade ao parto apresentou efeito significativo sobre a produção de leite, de forma que houve menor produção em vacas com idade ao parto de 20 a 36 meses (animais de primeiro parto), aumentando progressivamente em vacas com idade ao parto de 59 a 71 meses ( 5 a 6 anos) e diminuindo em vacas com idade acima de 85 meses ao parto ( $>7$ anos). À medida que os rebanhos têm mais tempo no programa de controle leiteiro, ocorre aumento da produção de leite.

Nas Tabelas 2 a 6 encontram-se os resultados médios de produção e composição do leite, de acordo com os fatores de variação: mês de controle leiteiro (Tabela 2), ano de controle leiteiro (Tabela 3), tempo de controle leiteiro do rebanho (Tabela 4), estádio da lactação (Tabela 5) e idade ao parto (Tabela 6). 
Tabela 1 - Produção, composição e escore de células somáticas do leite em 259 rebanhos de vacas da raça Holandesa no Rio Grande do Sul

Table 1 - Milk yield and composition and somatic cells score in 259 Holstein herds in Rio Grande do Sul, Brazil

\begin{tabular}{|c|c|c|c|c|c|}
\hline & $\begin{array}{c}\text { Produção de leite (L/vaca/dia) } \\
\text { Milk yield (L/cow/day) }\end{array}$ & $\begin{array}{c}\text { Gordura }(\%) \\
\text { Fat }\end{array}$ & $\begin{array}{c}\text { Proteína }(\%) \\
\text { Protein }\end{array}$ & $\begin{array}{l}\text { Lactose }(\%) \\
\text { Lactose }\end{array}$ & $\begin{array}{l}\text { Escore de células somáticas (0-9) } \\
\text { Somatic cells score }\end{array}$ \\
\hline № de dados & 165.267 & 165.267 & 165.267 & 157.755 & 165.267 \\
\hline Number of observat & & & & & \\
\hline $\begin{array}{l}\text { Média } \\
\text { Mean }\end{array}$ & 19,36 & 3,54 & 3,12 & 4,52 & 3,57 \\
\hline Desvio-padrão & 4,56 & 0,62 & 0,29 & 0,22 & 1,95 \\
\hline $\begin{array}{l}\text { Standard deviation } \\
\mathrm{CV}^{1}(\%)\end{array}$ & 23,5 & 17,6 & 9,4 & 4,8 & 54,7 \\
\hline
\end{tabular}

${ }^{1} \mathrm{CV}=$ coeficiente de variação (Coefficient of variation).

Tabela 2 - Produção, composição e escore de células somáticas do leite nos diferentes meses de controle leiteiro, em rebanhos da raça Holandesa no Rio Grande do Sul

Table 2 - Milk yield and composition and somatic cells score in different months of dairy control in Holstein herds of Rio Grande do Sul, Brazil

\begin{tabular}{|c|c|c|c|c|c|c|}
\hline $\begin{array}{l}\text { Mês do controle } \\
\text { Month of dairy control }\end{array}$ & $\begin{array}{c}\text { № de dados } \\
\text { Number of observations }\end{array}$ & $\begin{array}{c}\text { Produção de leite } \\
\text { (L/vaca/dia) } \\
\text { Milk yield (L/cow/day) }\end{array}$ & $\begin{array}{c}\text { Gordura }(\%) \\
\text { Fat }\end{array}$ & $\begin{array}{c}\text { Proteína }(\%) \\
\text { Protein }\end{array}$ & $\begin{array}{c}\text { Lactose }(\%) \\
\text { Lactose }\end{array}$ & $\begin{array}{l}\text { Escore de células } \\
\text { somáticas }(0-9) \\
\text { Somatic cells score }\end{array}$ \\
\hline Janeiro (Jan) & 13.827 & $18,48^{\mathrm{e}}$ & $3,41 \mathrm{~g}, \mathrm{~h}$ & $3,04^{\mathrm{e}}$ & $4,49^{\mathrm{d}}$ & $3,55^{\mathrm{e}}$ \\
\hline Fevereiro (Feb) & 12.747 & $18,52^{\mathrm{e}}$ & $3,45^{\mathrm{f}, \mathrm{g}}$ & $3,07^{\mathrm{d}}$ & $4,47^{\mathrm{e}}$ & $3,52^{b}$ \\
\hline Março (Mar) & 13.172 & $17,86^{\mathrm{f}}$ & $3,50^{\mathrm{d}}$ & $3,10^{\mathrm{c}}$ & $4,46^{\mathrm{e}}$ & $3,58^{a, b}$ \\
\hline Abril (Apr) & 13.240 & $18,04^{\mathrm{f}}$ & $3,62^{b}$ & $3,15^{b}$ & $4,46^{\mathrm{e}}$ & $3,65^{\mathrm{a}}$ \\
\hline Maio (May) & 13.413 & $18,70^{\mathrm{d}, \mathrm{e}}$ & $3,70^{\mathrm{a}}$ & $3,17^{\mathrm{a}}$ & $4,50^{\mathrm{d}}$ & $3,65^{\mathrm{a}}$ \\
\hline Junho (Jun) & 14.369 & $19,66^{\mathrm{c}}$ & $3,68^{\mathrm{a}}$ & $3,17^{\mathrm{a}}$ & $4,55^{b}$ & $3,61^{\mathrm{a}, \mathrm{b}}$ \\
\hline Julho (Jul) & 15.873 & $20,94^{\mathrm{b}}$ & $3,63^{b}$ & $3,17^{\mathrm{a}}$ & $4,55^{b}$ & $3,58^{a, b}$ \\
\hline Agosto (Aug) & 13.338 & $21,42^{\mathrm{a}}$ & $3,56^{\mathrm{c}}$ & $3,17^{\mathrm{a}}$ & $4,60^{\mathrm{a}}$ & $3,55^{b}$ \\
\hline Setembro (Sep) & 13.741 & $21,02^{b}$ & $3,55^{\mathrm{c}}$ & $3,18^{\mathrm{a}}$ & $4,55^{b}$ & $3,51^{b}$ \\
\hline Outubro (Oct) & 14.230 & $19,70^{\mathrm{c}}$ & $3,48^{\mathrm{d}, \mathrm{e}}$ & $3,12^{\mathrm{c}}$ & $4,54^{\mathrm{b}}$ & $3,54^{\mathrm{b}}$ \\
\hline Novembro (Nov) & 14.146 & $18,83^{d}$ & $3,45^{\mathrm{e}, \mathrm{f}}$ & $3,06^{\mathrm{d}, \mathrm{e}}$ & $4,52^{\mathrm{c}}$ & $3,53^{b}$ \\
\hline Dezembro (Dec) & 13.171 & $18,72^{\mathrm{d}, \mathrm{e}}$ & $3,40^{\mathrm{h}}$ & $3,02^{\mathrm{f}}$ & $4,51^{\mathrm{c}}$ & $3,54^{b}$ \\
\hline
\end{tabular}

Médias com letras diferentes entre meses têm diferença significativa $(P<0,05)$.

Means with different letters among months differ $(P<0.05)$ significantly.

Tabela 3 - Produção, composição e escore de células somáticas do leite, nos diferentes anos de controle leiteiro, em rebanhos da raça Holandesa no Rio Grande do Sul

Table 3 - Milk yield and composition and somatic cells score in different years of dairy control in Holstein herds of Rio Grande do Sul, Brazil

\begin{tabular}{|c|c|c|c|c|c|c|}
\hline $\begin{array}{l}\text { Ano do controle } \\
\text { Year of dairy control }\end{array}$ & $\begin{array}{c}\text { № de dados } \\
\text { Number of observations }\end{array}$ & $\begin{array}{c}\text { Produção de leite } \\
\text { (L/vaca/dia) } \\
\text { Milk yield (L/cow/day) }\end{array}$ & $\begin{array}{c}\text { Gordura }(\%) \\
\text { Fat }\end{array}$ & $\begin{array}{c}\text { Proteína }(\%) \\
\text { Protein }\end{array}$ & $\begin{array}{c}\text { Lactose }(\%) \\
\text { Lactose }\end{array}$ & $\begin{array}{l}\text { Escore de células } \\
\text { somáticas }(0-9) \\
\text { Somatic cells score }\end{array}$ \\
\hline 1998 & 5.218 & $18,92^{\mathrm{c}}$ & $3,52^{b, c}$ & $3,12^{\mathrm{d}}$ & n.d. & $3,08^{\mathrm{e}}$ \\
\hline 1999 & 23.641 & $19,67^{b}$ & $3,59^{\mathrm{a}}$ & $3,18^{\mathrm{a}}$ & $4,64^{\mathrm{a}}$ & $3,34^{\mathrm{d}}$ \\
\hline 2000 & 33.089 & $20,33^{\mathrm{a}}$ & $3,59^{a}$ & $3,17^{b}$ & $4,53^{c}$ & $3,56^{\mathrm{c}}$ \\
\hline 2001 & 42.552 & $19,57^{b}$ & $3,50^{\mathrm{c}}$ & $3,15^{\mathrm{c}}$ & $4,56^{b}$ & $3,68^{\mathrm{a}}$ \\
\hline 2002 & 40.838 & $18,59^{d}$ & $3,51^{b, c}$ & $3,04^{\mathrm{f}}$ & $4,44^{d}$ & $3,64^{\mathrm{a}, \mathrm{b}}$ \\
\hline 2003 & 19.929 & $18,58^{d}$ & $3,53^{b}$ & $3,06^{\mathrm{e}}$ & $4,42^{\mathrm{e}}$ & $3,58^{\mathrm{b}, \mathrm{c}}$ \\
\hline
\end{tabular}

Médias com letras diferentes entre anos têm diferença significativa $(P<0,05)$. n.d.: não disponível.

Means with different letters among year of dairy control differ $(P<0.05)$ significantly. n.d.: not available.

Efeito significativo do mês de controle leiteiro sobre a produção de leite foi observado, verificando-se produção maior nos meses de julho a setembro e menor nos meses de março a abril.

O teor médio de gordura foi de 3,54\%, com elevação significativa da porcentagem de gordura à medida que ocorreu aumento no ECS até o escore 5. A porcentagem de gordura foi maior nos anos 1999 e 2000. O estádio da lactação apresentou efeito significativo sobre a porcentagem de gordura do leite, ocorrendo aumento com o avanço da lactação, com o máximo teor acima de 221 dias. A porcentagem de gordura do leite apresentou valores mais baixos nas vacas com menor idade ao parto, apresentando maior teor nos animais com idade ao parto acima de 7 anos. A 
Tabela 4 - Produção, composição e escore de células somáticas do leite, em relação ao tempo em controle leiteiro, em rebanhos da raça Holandesa no Rio Grande do Sul

Table 4 - $\quad$ Milk yield and composition and somatic cells score according to time of farm on dairy control in Holstein herds of Rio Grande do Sul, Brazil

\begin{tabular}{|c|c|c|c|c|c|c|}
\hline $\begin{array}{l}\text { Tempo em controle (anos) } \\
\text { Time of dairy control (years) }\end{array}$ & $\begin{array}{c}\mathrm{N}-\text { de dados } \\
\text { Number of observations }\end{array}$ & $\begin{array}{c}\text { Produção de leite } \\
\text { (L/vaca/dia) } \\
\text { Milk yield (L/cow/day) }\end{array}$ & $\begin{array}{l}\text { Gordura }(\%) \\
\text { Fat }\end{array}$ & $\begin{array}{c}\text { Proteína }(\%) \\
\text { Protein }\end{array}$ & $\begin{array}{c}\text { Lactose }(\%) \\
\text { Lactose }\end{array}$ & $\begin{array}{l}\text { Escore de células } \\
\text { somáticas (0-9) } \\
\text { Somatic cells score }\end{array}$ \\
\hline 1 & 51.580 & $18,22^{\mathrm{d}}$ & $3,61^{\mathrm{a}}$ & $3,15^{\mathrm{a}}$ & $4,56^{\mathrm{a}}$ & 3,56 \\
\hline 2 & 43.583 & $19,31^{\mathrm{c}}$ & $3,56^{b}$ & $3,13^{b}$ & $4,51^{\mathrm{c}}$ & 3,58 \\
\hline 3 & 33.059 & $20,28^{a}$ & $3,48^{c}$ & $3,11^{\mathrm{c}}$ & $4,52^{b}$ & 3,62 \\
\hline 4 & 24.386 & $20,11^{b}$ & $3,46^{\mathrm{d}}$ & $3,06^{\mathrm{d}}$ & $4,47^{d}$ & 3,58 \\
\hline$\geq 5$ & 12.659 & $20,28^{a}$ & $3,45^{\mathrm{d}}$ & $3,07^{\mathrm{d}}$ & $4,43^{\mathrm{e}}$ & 3,41 \\
\hline
\end{tabular}

Médias com letras diferentes entre anos têm diferença significativa $(P<0,05)$.

Means with different letters among time of dairy control (years) differ $(P<0.05)$ significantly.

Tabela 5 - Produção, composição e escore de células somáticas do leite, em relação ao estádio da lactação, em rebanhos da raça Holandesa no Rio Grande do Sul

Table 5 - Milk yield and composition and somatic cells score according to lactation stage in Holstein herds of Rio Grande do Sul, Brazil

\begin{tabular}{|c|c|c|c|c|c|c|}
\hline $\begin{array}{l}\text { Estádio da lactação } \\
\text { (dias pós-parto) } \\
\text { Lactation stage (days in milk) }\end{array}$ & $\begin{array}{c}\text { № de dados } \\
\text { Number of observations }\end{array}$ & $\begin{array}{c}\text { Produção de leite } \\
\text { (L/vaca/dia) } \\
\text { Milk yield (L/cow/day) }\end{array}$ & $\begin{array}{c}\text { Gordura }(\%) \\
\text { Fat }\end{array}$ & $\begin{array}{c}\text { Proteína }(\%) \\
\text { Protein }\end{array}$ & $\begin{array}{c}\text { Lactose }(\%) \\
\text { Lactose }\end{array}$ & $\begin{array}{l}\text { Escore de células } \\
\text { somáticas }(0-9) \\
\text { Somatic cells score }\end{array}$ \\
\hline$<60$ & 30.332 & $23,94^{\mathrm{a}}$ & $3,42^{\mathrm{c}}$ & $2,99^{\mathrm{c}}$ & $4,58^{\mathrm{a}}$ & $2,96^{\mathrm{d}}$ \\
\hline $61-120$ & 32.586 & $21,97^{b}$ & $3,39^{\mathrm{d}}$ & $2,95^{\mathrm{d}}$ & $4,58^{\mathrm{a}}$ & $3,20^{\mathrm{c}}$ \\
\hline $121-220$ & 51.563 & $18,68^{c}$ & $3,53^{b}$ & $3,10^{b}$ & $4,51^{b}$ & $3,65^{b}$ \\
\hline$>220$ & 50.786 & $15,63^{d}$ & $3,71^{\mathrm{a}}$ & $3,32^{\mathrm{a}}$ & $4,45^{\mathrm{c}}$ & $4,08^{a}$ \\
\hline
\end{tabular}

Médias com letras diferentes entre estádios têm diferença significativa $(P<0,05)$.

Means with different letters among lactation stages (days in milk) differ $(P<0.05)$ significantly.

Tabela 6 - Produção, composição e escore de células somáticas do leite, em relação à idade ao parto, em rebanhos da raça Holandesa no Rio Grande do Sul

Table 6 - Milk yield and composition and somatic cells score according to age at calving in Holstein herds of Rio Grande do Sul, Brazil

\begin{tabular}{|c|c|c|c|c|c|c|}
\hline $\begin{array}{l}\text { Idade ao parto (meses) } \\
\text { Age at calving (months) }\end{array}$ & $\begin{array}{c}\text { № de dados } \\
\text { Number of observations }\end{array}$ & $\begin{array}{c}\text { Produção de leite } \\
\text { (L/vaca/dia) } \\
\text { Milk yield (L/cow/day) }\end{array}$ & $\begin{array}{c}\text { Gordura }(\%) \\
\text { Fat }\end{array}$ & $\begin{array}{c}\text { Proteína }(\%) \\
\text { Protein }\end{array}$ & $\begin{array}{c}\text { Lactose }(\%) \\
\text { Lactose }\end{array}$ & $\begin{array}{l}\text { Escore de células } \\
\text { somáticas }(0-9) \\
\text { Somatic cells score }\end{array}$ \\
\hline $20-32$ & 37.803 & $18,09^{\mathrm{f}}$ & $3,51^{\mathrm{c}}$ & $3,10^{\mathrm{d}}$ & $4,61^{\mathrm{a}}$ & $2,79^{\mathrm{e}}$ \\
\hline $33-45$ & 36.225 & $19,28^{\mathrm{d}}$ & $3,53^{b}$ & $3,14^{\mathrm{a}}$ & $4,54^{b}$ & $3,30^{\mathrm{d}}$ \\
\hline $46-58$ & 28.566 & $20,16^{\mathrm{c}}$ & $3,53^{b}$ & $3,13^{b}$ & $4,49^{\mathrm{c}}$ & $3,75^{\mathrm{c}}$ \\
\hline $59-71$ & 21.891 & $20,57^{\mathrm{a}}$ & $3,54^{\mathrm{c}}$ & $3,12^{b, c}$ & $4,47^{\mathrm{d}}$ & $4,02^{b}$ \\
\hline $72-84$ & 15.212 & $20,43^{b}$ & $3,55^{b}$ & $3,12^{\mathrm{c}}$ & $4,45^{\mathrm{f}}$ & $4,17^{\mathrm{a}}$ \\
\hline$>85$ & 25.570 & $18,78^{\mathrm{e}}$ & $3,58^{\mathrm{a}}$ & $3,12^{b, c}$ & $4,46^{\mathrm{e}}$ & $4,16^{\mathrm{a}}$ \\
\hline
\end{tabular}

Médias com letras diferentes entre grupos etários têm diferença significativa $(P<0,05)$.

Means with different letters among etary groups (age at calving) differ $(P<0.05)$ significantly.

concentração de gordura apresentou tendência de queda com o aumento do tempo do rebanho em controle leiteiro. Nos meses de verão, o conteúdo de gordura $(3,41$ a 3,49\%) foi menor que nos meses de inverno (em torno de 3,7\%).

O teor médio de proteína no leite no total de observações foi de $3,12 \%$. O ano de controle leiteiro mostrou efeito significativo sobre o teor de proteína do leite. Em 1999 foram observados os maiores valores, ocorrendo, posteriormente, diminuição. O ECS apresentou efeito sobre a concentração de proteína do leite, observando-se acréscimo no teor de proteína com o aumento do ECS. O teor de proteína do leite foi afetado pelo mês de controle leiteiro, registrando-se teor de proteína maior nos meses de maio a setembro (em torno de 3,18\%) e menor teor nos meses de verão, sendo dezembro o mês com menor valor $(3,02 \%)$. O teor de proteína do leite foi menor nos primeiros 60 dias de lactação, apresentando elevação com o avanço da lactação. A idade ao parto afetou o teor de proteína do leite, obtendo-se maior valor nas vacas com partos de 33 a 45 meses de idade e menor nas vacas de primeiro parto (de 20 a 32 meses). À medida que o tempo em controle leiteiro do rebanho aumentou, houve tendência de diminuição nos teores de proteína do leite.

O teor médio de lactose foi de 4,52\%, que diminuiu significativamente entre os anos de controle (1999 a 2003). Conforme o ECS aumentou, o teor de lactose no leite diminuiu. O teor de lactose reduziu significativamente com 
Tabela 7 - Produção e composição do leite, em relação ao escore de células somáticas (ECS), em rebanhos da raça Holandesa no Rio Grande do Sul

Table 7 - Milk yield and composition according to somatic cells score (SCS) in Holstein herds of Rio Grande do Sul, Brazil

\begin{tabular}{|c|c|c|c|c|c|}
\hline $\begin{array}{l}\text { ECS } \\
S C S\end{array}$ & $\begin{array}{c}\text { № de dados } \\
\text { Number of observations }\end{array}$ & $\begin{array}{c}\text { Produção de leite (L/vaca/dia) } \\
\text { Milk yield (L/cow/day) }\end{array}$ & $\begin{array}{c}\text { Gordura }(\%) \\
\text { Fat }\end{array}$ & $\begin{array}{l}\text { Proteína }(\%) \\
\text { Protein }\end{array}$ & $\begin{array}{c}\text { Lactose }(\%) \\
\text { Lactose }\end{array}$ \\
\hline 0 & 30.356 & $21,44^{\mathrm{a}}$ & $3,40^{\mathrm{f}}$ & $3,00^{\mathrm{f}}$ & $4,64^{b}$ \\
\hline 1 & 1.063 & $20,92^{b}$ & $3,48^{\mathrm{e}}$ & $3,08^{\mathrm{d}, \mathrm{e}}$ & $4,69^{\mathrm{a}}$ \\
\hline 2 & 10.702 & $20,46^{\mathrm{c}}$ & $3,49^{\mathrm{d}, \mathrm{e}}$ & $3,06^{\mathrm{e}}$ & $4,60^{\mathrm{c}}$ \\
\hline 3 & 30.533 & $19,55^{\mathrm{d}}$ & $3,54^{\mathrm{b}, \mathrm{c}, \mathrm{d}}$ & $3,10^{\mathrm{d}}$ & $4,57^{\mathrm{d}}$ \\
\hline 4 & 35.321 & $18,58^{\mathrm{f}, \mathrm{g}}$ & $3,59^{\mathrm{a}, \mathrm{b}}$ & $3,15^{\mathrm{c}}$ & $4,51^{\mathrm{e}}$ \\
\hline 5 & 28.115 & $18,02^{\mathrm{h}}$ & $3,61^{\mathrm{a}}$ & $3,19^{b}$ & $4,45^{\mathrm{f}}$ \\
\hline 6 & 16.426 & $18,39^{\mathrm{g}, \mathrm{h}}$ & $3,58^{\mathrm{a}, \mathrm{b}, \mathrm{c}}$ & $3,20^{\mathrm{a}, \mathrm{b}}$ & $4,39^{\mathrm{g}}$ \\
\hline 7 & 8.030 & $19,24^{\mathrm{d}, \mathrm{e}}$ & $3,54^{\mathrm{b}, \mathrm{c}}$ & $3,19^{\mathrm{b}}$ & $4,35^{\mathrm{h}}$ \\
\hline 8 & 3.494 & $19,21^{\mathrm{d}, \mathrm{e}}$ & $3,52^{\mathrm{c}, \mathrm{d}, \mathrm{e}}$ & $3,20^{\mathrm{b}}$ & $4,30^{\mathrm{i}}$ \\
\hline 9 & 1.227 & $18,89^{\mathrm{e}, \mathrm{f}}$ & $3,56^{\mathrm{a}, \mathrm{b}, \mathrm{c}}$ & $3,22^{\mathrm{a}}$ & $4,23^{j}$ \\
\hline
\end{tabular}

Médias com letras diferentes entre valores de ECS têm diferença significativa $(p<0,05)$.

Means with different letters among SCS values differ $(p<0.05)$ significantly.

o avanço da lactação, de modo que, nos primeiros 60 dias de lactação, observou-se o maior teor deste glicídeo. A lactose reduziu significativamente com o aumento da idade ao parto. O tempo do rebanho em controle leiteiro tendeu a diminuir nos teores de lactose do leite. O maior teor de lactose foi registrado no mês de agosto $(4,6 \%)$ e o menor, no mês de março $(4,46 \%)$.

Consta na Tabela 7 a relação do ECS com os parâmetros de produção e composição do leite. O ECS médio nos rebanhos analisados foi de 3,57 , que corresponde à CCS em torno de 390.000 células $/ \mathrm{mL}$. O ECS aumentou progressivamente nos anos de controle de 1998 a 2001, com posterior decréscimo até 2003. O ECS aumentou à medida que avançou o estádio da lactação. A idade ao parto apresentou efeito significativo sobre o ECS, com aumento progressivo nos animais mais velhos.

Valores gerais de produção leiteira e de composição química e contagem de células somáticas são apresentados a partir de mais de 165.000 observações realizadas em seis anos. O nível de produção global neste trabalho reflete boas condições de manejo e de potencial genético. Krug (2001) cita produção média de 10,53 L/vaca/dia em rebanhos do Rio Grande do Sul. Outros estudos em rebanhos da raça Holandesa mostram médias de produção inferiores às encontradas neste estudo: 16,7 L/vaca/dia em Pernambuco (Nunes Jr. et al., 1996) e 17,02 L/vaca/dia em Minas Gerais (Araújo et al., 2000). Bajaluk et al. (1999), em rebanhos de raça Holandesa no Paraná, encontraram maior produção média $(24,77 \mathrm{~L} / \mathrm{vaca} / \mathrm{dia})$.

A maior produção verificada no inverno pode ser resultado das diferenças nas fontes de alimentação ao longo do ano. Forrageiras de melhor qualidade, como as gramíneas temperadas dos gêneros Lolium e Avena, são oferecidas durante os meses de inverno (junho a setembro), quando se observam as melhores produções, enquanto, nos meses de verão, são oferecidas gramíneas tropicais dos gêneros Cynodon, Sorghum e Pennisetum (Fontaneli \& Fontaneli, 2000). Nos meses de verão (dezembro a abril), a menor produção observada pode ser decorrente da menor qualidade das forrageiras tropicais (Corsi \& Martha, 1998) e pelo estresse por calor (Ray et al., 1992). Variações de produção de leite ao longo do ano foram encontradas também por Teixeira et al. (2003), em rebanhos de Minas Gerais. A diminuição da produção de leite com o aumento de células somáticas indica que vacas com processos inflamatórios mamários sofrem redução significativa na produção, coincidindo com os dados reportados por Carvalho et al. (2002). A maior produção entre 1999 e 2001 pode ter relação com os melhores preços do leite nesses anos, o que pode ter influenciado a alimentação dos animais. O decréscimo na produção observado no ano 2003 foi atribuído à queda nos investimentos em alimentação nos rebanhos gaúchos, conseqüência da defasagem do preço do leite e do momento propício à cultura da soja, que constitui a linha primária dos produtores da região. Vários autores citam variações na produção de leite nos diferentes estádios da lactação. Ribas et al. (2001) afirmam que a maior produção ocorre entre 45 e 54 dias de lactação, coincidindo com os dados deste trabalho.

A produção média geral de gordura foi superior à observada em rebanhos no Paraná (Bajaluk et al., 1999; Ribas et al., 1996) e em Minas Gerais (Araújo et al., 2000). O teor de gordura aumentou significativamente com o avanço da lactação, confirmando os achados de Ribas et al. (2001). Marques et al. (2002), no Rio Grande do Sul, verificaram aumentos lineares no teor de gordura com o aumento da 
contagem de células somáticas, o que está de acordo com os dados deste trabalho. Em contraste, Pereira et al. (1999) relatam que a gordura do leite diminui com o aumento de células somáticas.

O valor médio de proteína no leite foi próximo ao encontrado por Bajaluk et al. (1999), no Paraná, porém menor que o relatado por Ribas et al. (2001), na Região Sul do Brasil, e por Brito \& Portugal (2003), na Região Sudeste do Brasil. O aumento da proteína do leite com o aumento de células somáticas neste estudo também foi observado por Carvalho et al. (2002). Esse aumento é decorrente não só da proteína celular, mas também da mudança na permeabilidade da membrana alveolar mamária, levando a aumento do influxo de lactalbumina e imunoglobulinas para o interior da glândula (Pereira et al., 1999). Concomitantemente ao aumento das proteínas séricas do leite, ocorre a diminuição na caseína, pela sua degradação por proteases bacterianas e leucocitárias e pela diminuição de sua síntese, o que constitui efeito indesejável (Santos \& Fonseca, 2002). Ribas et al. (2003) observaram que a proteína láctea comporta de modo inverso à produção de leite ao longo da lactação, ocorrendo elevação gradual até o final da lactação, corroborando os dados deste trabalho. O maior teor de proteína, gordura e lactose no leite durante os meses de inverno pode estar relacionado à melhor qualidade nutritiva das pastagens temperadas utilizadas pelos rebanhos, em comparação às pastagens tropicais de verão.

O valor médio de lactose foi inferior ao verificado por Akers (2002), em vacas da raça Holandesa nos Estados Unidos, e por Auldist et al. (1998), na Nova Zelândia. O valor encontrado neste trabalho se aproxima ao de trabalhos realizados no Brasil, em amostras de tanque, nas Regiões Sul e Sudeste (Ribas et al., 2003; Machado et al. 2003), onde a média é de 4,5\%. Embora seja considerado que a lactose é o componente lácteo de menor variação (Manson, 2003), neste estudo foram encontradas diferenças significativas em relação a todas as variáveis consideradas. A diminuição do teor de lactose conforme o aumento das células somáticas foi observado também por Marques et al. (2002), no Rio Grande do Sul. Esta redução pode ser resultado da menor capacidade de síntese de lactose pelo epitélio mamário infectado, da utilização da lactose pelos patógenos intramamários e da perda de lactose para a corrente sanguínea, decorrente do aumento de permeabilidade de membrana (Machado et al., 2000). Auldist et al. (1998) observaram diminuição do teor de lactose com o avanço da lactação em rebanhos da Nova Zelândia, o que está de acordo com os resultados deste trabalho.

A contagem de células somáticas foi expressa como escore (ECS), sendo encontrados números menores que os relatados em outras regiões do Brasil (Ostrensky et al., 2000; Teixeira et al., 2003), o que pode ser atribuído à aplicação das recomendações de manejo da ordenha, transmitidas pelo corpo técnico das cooperativas. Schukken et al. (1990), nos Estados Unidos, verificaram tendência de diminuição das células somáticas dos rebanhos ao longo dos anos de amostragem, situação contrária à observada neste trabalho, enquanto Ostrensky et al. (2000) observaram elevação do ECS com o avanço da lactação. Esses dados divergem dos obtidos neste estudo, mas corroboram os descrito por Brito (2003). Cunha et al. (2002), em rebanhos da raça Holandesa de Minas Gerais, observaram aumento na CCS com a idade, como observado neste trabalho.

\section{Conclusões}

É importante considerar fatores ambientais como ano, mês, idade ao parto e estádio de lactação quando se estudam as variações na produção e na composição química do leite. A avaliação de células somáticas no leite comprovou efeitos significativos desta característica sobre a produção e a composição de leite. No inverno, a produção total de leite foi maior que no verão, resultado da melhor qualidade de forragens. Essa época também favoreceu maior conteúdo dos componentes analisados. Os valores médios globais da composição química do leite nos rebanhos estudados foram de $3,54 \%$ de gordura, $3,12 \%$ de proteína e $4,52 \%$ de lactose. A média global estimada de contagem de células somáticas foi de 390.000 células $/ \mathrm{mL}$.

\section{Literatura Citada}

AKERS, R.M. Lactation and mammary gland. Ames: Iowa State University Press, 2002. 278p.

ARAÚJO, C.V.; GONÇALVES, T.M.; AQUINO, L.H. et al. Fatores não genéticos nas produções de leite e de gordura em rebanhos da raça Holandesa no estado de Minas Gerais. Ciência e Agrotecnologia, v.24, p.766-772, 2000.

AULDIST, M.J.; WALSH, B.J.; THOMPSON, N.A. Seasonal and lactational influences on bovine milk composition in New Zealand. Journal of Dairy Research, v.65, p.401-411, 1998.

BAJALUK, S.A.B.; RIBAS, N.P.; MONARDES, H.G. et al. Efeito de fatores ambientais sobre a produção de leite, percentagem de gordura e percentagem de proteína em vacas da raça Holandesa no estado do Paraná. In: REUNIÃO ANUAL DA SOCIEDADE BRASILEIRA DE ZOOTECNIA, 36., 1999, Porto Alegre. Anais.. Porto Alegre: Sociedade Brasileira de Zootecnia, 1999. p.36.

BITENCOURT, D.; XAVIER, S.S.; BRIZOLA, R.M. A situação atual da pecuária leiteira no Rio Grande do Sul e tendências futuras. In NOVOS DESAFIOS PARA A PRODUÇÃO LEITEIRA NO RIO GRANDE DO SUL, 2000, Porto Alegre. Anais... Porto Alegre: Universidade Federal do Rio Grande do Sul, 2000. p.11-24.

BRITO, J.R.F. Células somáticas no leite: uma revisão. CBLQ em Revista, v.1, p.11-17, 2003.

BRITO, J.R.F.; PORTUGAL, J.A.B. Panorama da qualidade do leite na região Sudeste: Espírito Santo, Minas Gerais e Rio de Janeiro. 
In:__ (Eds.) Diagnóstico da qualidade do leite, impacto para a indústria e a questão dos resíduos de antibióticos. Juiz de Fora: Embrapa Gado de Leite, 2003. p.47-62.

CARVALHO, G.F.; CUNHA, R.P.L.; MOLINA, L.R. et al. Milk yield, somatic cell count and physico-chemical characteristics of raw milk collected from dairy cows in Minas Gerais State. In: CONGRESSO PANAMERICANO DE QUALIDADE DO LEITE E CONTROLE DA MASTITE, 2., 2002, Ribeirão Preto. Anais... Ribeirão Preto, 2002 (CD-ROM)

CORSI, M.; MARTHA JR., G.B. Manejo de pastagens para produção de carne e leite. In: PEIXOTO, A.M.; MOURA, J.C.; FARIA, V.P. (Eds.) Manejo de pastagens de Tifton, Coastcross e Estrela. Piracicaba: Escola Superior de Agricultura Luiz de Queiroz, 1998. p.55-85.

CUNHA, R.P.; MOLINA, L.R.; CARVALHO, G.F. et al. Parturition order, milk yield, somatic cell count and physico-chemical characteristics of milk. In: CONGRESSO PANAMERICANO DE QUALIDADE DO LEITE E CONTROLE DA MASTITE, 2., 2002, Ribeirão Preto. Anais... Ribeirão Preto: 2002 (CD-ROM).

DÜRR, J.W. Programa nacional de melhoria da qualidade do leite: uma oportunidade única. In: DÜRR, J.W.; CARVALHO, M.P.; SANTOS, M.V. (Eds.) O compromisso com a qualidade do leite no Brasil. Passo Fundo: Editora Universidade de Passo Fundo, 2004. p.38-55.

FONTANELI, R.E.; FONTANELI, R. Cadeia forrageira para a produção de leite no Rio Grande do Sul. In: FONTANELI, R.E; DÜRR, J.W.; FONTANELI, R. (Eds.) Sistemas de produção de leite. Passo Fundo: Universidade de Passo Fundo, 2000. p. 59-85.

GONZÁLEZ, F.H.D.; CAMPOS, R. O leite como indicador metabólico-nutricional em vacas. A Hora Veterinária, v.22, p.36-38, 2003.

INSTITUTO BRASILEIRO DE GEOGRAFIA E ESTATÍSTICA IBGE. 2004. Disponível em: <www.ibge.gov.br> Acesso em: $10 / 01 / 04$

KRUG, E.E. Sistemas de produção de leite: identificação de benchmarking. Porto Alegre: Pallotti, 2001. 256p.

MACHADO, P.F.; PEREIRA, A.R.; SARRIES, G.A. Composição do leite de tanques de rebanhos brasileiros distribuídos segundo sua contagem de células somáticas. Revista Brasileira de Zootecnia, v,29, p.1883-1886, 2000.

MACHADO, P.F.; CASSOLI, L.D.; COLDEBELLA, A. et al. Panorama da qualidade do leite na Região Sudeste: São Paulo. In: BRITO, J.R.; PORTUGAL, J.A (Eds.) Diagnóstico da qualidade do leite, impacto para a indústria e a questão dos resíduos de antibióticos. Juiz de Fora: Embrapa Gado de Leite, 2003. p.39-48.

MANSON, S. 2003. How the cow makes lactose. Disponível em: $<$ http://www.westerndairyscience.com> Acesso em: 17/07/03.

MARQUES, L.T.; BALBINOTTI, M.; FISCHER,V. Variação da composição química do leite de acordo com a contagem de células somáticas. In: CONGRESSO PANAMERICANO DE QUALIDADE DO LEITE E CONTROLE DE MASTITE, 2., 2002, Ribeirão Preto. Anais... Ribeirão Preto, 2002 (CD-ROM).

MONARDES, H. Programa de pagamento de leite por qualidade em Quebec, Canadá. In: SIMPÓSIO INTERNACIONAL SOBRE QUALIDADE DO LEITE, 1., 1998, Curitiba. Anais... Curitiba: Universidade Federal do Paraná, 1998. p.40-43.

NUNES JR., R.C.; BARBOSA, S.B.; MANSO, H.C. Avaliação da produção leiteira de vacas Holandesas na região Agreste de Pernambuco. In: REUNIÃO ANUAL DA SOCIEDADE
BRASILEIRA DE ZOOTECNIA, 33., 1996, Fortaleza. Anais.. Fortaleza: Sociedade Brasileira de Zootecnia, 1996. p.100-103. OSTRENSKY, A.; RIBAS, N.P.; MONARDES, H.G. et al. Fatores de ambiente sobre o escore de células somáticas no leite de vacas da raça Holandesa do Paraná. In: REUNIÃO ANUAL DA SOCIEDADE BRASILEIRA DE ZOOTECNIA, 37., 2000 , Viçosa, MG. Anais... Viçosa, MG: Sociedade Brasileira de Zootecnia, 2000. p.229.

PEREIRA, A.R.; PRADA e SILVA, L.F.; MOLON, L.K. et al. Efeito do nível de células somáticas sobre os constituintes do leite. I. Gordura e proteína. Revista Brasileira de Pesquisa Veterinária e Ciência Animal, v.36, p.121-124, 1999.

RAY, D.E.; HALBACH, T.J.; ARMSTRONG, D.V. Season and lactation number effects on milk production and reproduction of dairy cows in Arizona. Journal of Dairy Science, v.75, p.2976-2983, 1992

RIBAS, N.P.; MONARDES, H.G.; MOLENTO, C.F.M. et al. Estudo dos efeitos de meio ambiente sobre características produtivas de vacas da raça Holandesa no Estado do Paraná. In: REUNIÃO ANUAL DA SOCIEDADE BRASILEIRA DE ZOOTECNIA, 33. 1996, Fortaleza. Anais... Fortaleza: Sociedade Brasileira de Zootecnia, 1996. p.33.

RIBAS, N.P.; MONARDES, H.G.; BAJALUK, S. et al. Produção diária de leite, porcentagens de gordura e proteína em vacas da raça Holandesa no Estado do Paraná. Revista Batavo, v. 8 , p.26-33, 2001

RIBAS, N.P.; PAULA, M.C.; ANDRADE, U.V.C. et al. Sólidos totais em amostras de leite de tanques nos estados de Santa Catarina, Paraná e São Paulo. In: BRITO, J.R.; PORTUGAL, J.A. (Eds.) Diagnóstico da qualidade do leite, impacto para a indústria e a questão dos resíduos de antibióticos. Juiz de Fora: Embrapa Gado de Leite, 2003. p.19-26.

SANTOS, M.V.; FONSECA, L.F. $2^{\circ}$ Curso on-line de qualidade do leite. Disponível em: <http:www.milkpoint.com.br> Acesso em: 20/04/02.

STATISTICAL ANALYSES SYSTEM - SAS. User's guide: statistics. Cary: 2001

SCHUKKEN, Y.H.; BUURMAN, J.; BRAND, A. et al. Population dynamics of bulk milk somatic cell counts. Journal of Dairy Science, v.73, p.1343-1350, 1990.

SHOOK, G.E. Approaches to summarizing somatic cell count which improve interpretability. In: NATIONAL MASTITIS COUNCIL ANNUAL MEeting, 21., 1982, Pennsylvania. Proceedings.. Pennsylvania: 1982. p.150-166.

SUTTON, J.D. Altering milk composition by feeding. Journal of Dairy Science, v.72, p.2801-2814, 1989.

TEIXEIRA, N.M.; FREITAS, A.F.; BARRA, R.B. Influência de fatores de meio ambiente na variação mensal da composição e contagem de células somáticas do leite em rebanhos no estado de Minas Gerais. Arquivos Brasileiros de Medicina Veterinária e Zootecnia, v.55, p.4911-499, 2003. 